\title{
Silicotungstic Acid Modified Bentonite: An Efficient Catalyst for Synthesis of Acetal Derivatives of Aldehydes and Ketones
}

\author{
Reshu Chaudhary, Monika Datta* \\ Department of Chemistry, University of Delhi, New Delhi, India.

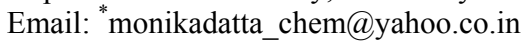 \\ Received September $7^{\text {th }}, 2013$; revised October $7^{\text {th }}, 2013$; accepted October $19^{\text {th }}, 2013$
}

Copyright (C) 2013 Reshu Chaudhary, Monika Datta. This is an open access article distributed under the Creative Commons Attribution License, which permits unrestricted use, distribution, and reproduction in any medium, provided the original work is properly cited.

\begin{abstract}
Acetals and ketals are among the important materials of organic synthesis and as protecting agent of carbonyl functionality. A milder, efficient and green synthesis of acetals and ketals has been developed using Silicotungstic acid modified Bentonite (STA-Ben) as a catalyst. STA-Ben has been synthesized and characterized by various analytical techniques. It has been found to be an efficient and reusable catalyst for the synthesis of acetyl derivatives in excellent yields. In order to elucidate the efficiency of the STA-Ben as catalyst, reaction has also been performed using various catalysts. The reaction conditions (time and amount of catalyst) have been optimized using various catalysts. The products of the various reactions have been characterized by FT-IR, NMR.
\end{abstract}

Keywords: Silicotungstic Acid; Bentonite; Aldehydes; Ketones

\section{Introduction}

Acetals and ketals are one of the most important perfume materials and industrial materials of organic synthesis. The protection of carbonyl functionality as an acetal or thioacetal derivative is a common practice in organic synthesis owing to their stability under mild acidic and basic conditions. They are generally obtained by the condensation of carbonyl compound with acetic anhydride [1], diols, dithiols and orthoformates [2-5], using Lewis acids as catalysts. A variety of catalysts are employed for this purpose like $\mathrm{CoCl}_{2}$ [6], $\mathrm{NiCl}_{2}$ [2], $\mathrm{HCl}$ [7], $\mathrm{HClO}_{4}$ [8], sulfated zirconia [9] etc. But the most recent methods employ MMT-K10 [10], ionic liquids [11], metal cation exchanged MMT [12], natural kaolinite clay [3], silica sulfuric acid [13], $\mathrm{TaCl}_{5}$-silicagel [14] as catalysts. However, many of these methods have some drawbacks such as low yields of the products, long reaction times, harsh reaction conditions, difficulties in workup. Moreover, the main disadvantage of almost all existing methods is that the catalysts are destroyed in the work-up procedure and cannot be recovered or reused.

${ }^{*}$ Corresponding author.
Therefore, there is further scope to explore mild and efficient methods for acetalization of carbonyl compounds.

Solid acids offer many advantages by their nature, over soluble counterparts such as aluminium chloride and hydrogen fluoride. The substitution of liquid acids by solids as catalysts for organic synthesis offers a potential for superior effectiveness and environmental integrity. Although they differ in structure from liquid acids, solid acid catalysts work by the same principle. Among the solid acids, heteropoly acids (HPAs) have been extensively studied as acid catalysts for many reactions and found industrial applications in several processes [15]. The Keg- gin-type HPAs typically represented by the formula $\mathrm{H}_{8-\mathrm{x}}\left[\mathrm{XM}_{12} \mathrm{O}_{40}\right]$, where $\mathrm{X}$ is the heteroatom (e.g., $\mathrm{P}^{5+}$ or $\left.\mathrm{Si}^{4+}\right), \mathrm{x}$ is its oxidation state and $\mathrm{M}$ is the addenda atom (usually $\mathrm{Mo}^{6+}$ or $\mathrm{W}^{6+}$ ), are the most important catalysts, especially $\mathrm{H}_{3} \mathrm{PW}_{12} \mathrm{O}_{40}$ (PW), $\mathrm{H}_{3} \mathrm{PMo}_{12} \mathrm{O}_{40}$ (PMo) and $\mathrm{H}_{4} \mathrm{SiW}_{12} \mathrm{O}_{40}(\mathrm{SiW})$ [16]. They are more active than the conventional catalysts, such as mineral acids, ion-exchange resins, zeolites, $\mathrm{SiO}_{2} / \mathrm{Al}_{2} \mathrm{O}_{3}$ and $\mathrm{H}_{3} \mathrm{PO}_{4} / \mathrm{SiO}_{2}$ [17$19]$.

HPAs have several advantages over liquid acid catalysts, including being non-corrosive and environmen- 
tally benign. Thus, they present fewer disposal problems and more economically and environmentally attractive. Heteropoly acids (HPAs) due to their strong acidity have attracted much interest as the catalysts mostly in homogeneous systems $[20,22]$. It's not easy to separate HPA from reaction mixture and reuse it unless it is supported on some catalyst. Clays have also been proposed as suitable acid catalysts $[23,24]$. Clays are furthermore used as adsorbents, decoloration agents, ion exchangers, and catalysts [25]. The use of clays, as heterogeneous catalysts, offers many advantages over homogeneous acid catalysts such as ease of separation, mild reaction conditions, better selectivity of the desired product, and elimination of waste disposal problems. In a large number of organic reactions clays have been used as catalysts on laboratory/ industrial scales. The properties of clay can further be improved by making pillared clays. Pillared clays are clays with high permanent porosity obtained by separating the clay sheets by a molecular prop or pillaring agent. These pillaring agents can be organic, organometallic, or inorganic complexes, preferably of a high positive charge. Pillared clay (PILC) possesses several interesting properties, such as large surface area, high pore volume and tunable pore size (from micropore to mesopore), high thermal stability, strong surface acidity and catalytic active substrates/metal oxide pillars. These unique characteristics make PILC an attractive material in catalytic reactions. It can be made either as catalyst support or directly used as catalyst [26-28].

In the present work silicotungstic acid (a heteropoly acid) modified bentonite have been synthesized to explore the properties of both clay and silicotungstic acid (a heteropoly acid). This makes it possible to carry out the catalytic process at a lower catalyst concentration and/or at a lower temperature. Further, catalysis of heteropoly acid lacks side reactions.

\section{Experimental}

\subsection{Catalyst Preparation}

\section{Na-Bentonite}

$1.0 \mathrm{~g}$ of Bentonite clay was added into a $250 \mathrm{ml}$ conical flask containing $50 \mathrm{ml}$ of $1.0 \mathrm{M} \mathrm{NaCl}$ this clay suspension was stirred for 16 hours. The residue after centrifugation was washed several times with double distilled water till complete removal of chloride ions. The residue thus obtained after above procedure was dried in an oven at $100^{\circ} \mathrm{C}$ to generate the $\mathrm{Na}$ form of the Bentonite (Na-Ben).

\section{Al-Pillared Bentonite (Al-Ben)}

In a $250 \mathrm{ml}$ conical flask containing $1.0 \mathrm{~g}$ of Na-Ben in $100 \mathrm{ml}$ of double distilled water, $50 \mathrm{ml}$ of the pillaring solution (keggin ion) was gradually added with vigorous stirring for 16 hours. The residue was washed several times with double distilled water till the complete removal of chloride ions was confirmed by $\mathrm{AgNO}_{3}$ test. The residue, thus obtained was dried in an oven at $100^{\circ} \mathrm{C}$ is referred to as Al-Pillared Bentonite (Al-Ben) [29,30].

\section{Acid Activated Bentonite ( $\mathrm{H}^{+}$-Ben)}

$5.0 \mathrm{~g}$ of Na-Ben was added into a $100 \mathrm{ml}$ beaker containing $50 \mathrm{ml}$ of $3 \mathrm{~N} \mathrm{H}_{2} \mathrm{SO}_{4}$, this mixture was exposed to microwave radiation for 30 minutes. The residue was washed several times with double distilled water till the complete removal of $\mathrm{SO}_{4}^{2-}$ ions was confirmed by $\mathrm{BaCl}_{2}$ test. The residue thus obtained was dried in an oven at $100^{\circ} \mathrm{C}$ to generate the Acid activated Bentonite ( $\mathrm{H}^{+}$-Ben) [28].

\section{Pillared Acid Activated Bentonite (PAA-Ben)}

$1.0 \mathrm{~g}$ of $\mathrm{H}^{+}$Ben, was added into a $250 \mathrm{ml}$ conical flask containing $100 \mathrm{ml}$ of double distilled water. $50 \mathrm{ml}$ of pillaring solution was gradually added with vigorous stirring for 16 hours. The residue was washed several times with double distilled water till the complete removal of chloride ions was confirmed by $\mathrm{AgNO}_{3}$ test. The residue thus obtained was dried in an oven at $100^{\circ} \mathrm{C}$ and is referred to as Pillared Acid Activated Bentonite (PAA-Ben).

\section{Silicotungstic Acid Modified Bentonite (STA-Ben)}

In a $250 \mathrm{ml}$ conical flask, $1.0 \mathrm{~g}$ Na-Ben was suspended in $50 \mathrm{ml}$ double distilled water. To this, aqueous solution of silicotungstic acid (100 mg) was added drop wise and then stirred for 16 hours. After this, the mixture was filtered and washed with double distilled water to remove the excess of silicotungstic acid. The product was dried at $100^{\circ} \mathrm{C}$.

\subsection{General Procedure for the Synthesis of Acetal Derivative of Aldehydes and Ketones}

In order to elucidate the role of the STA-Ben as catalyst, a controlled reaction was carried out using STA, bentonite, Al-Ben, $\mathrm{H}^{+}$-Ben, PAA-Ben and STA-Ben as catalyst with benzaldehyde as reactant. The best results were obtained with STA-Ben in microwave.

A number of aromatic/aliphatic aldehydes or ketones $(10 \mathrm{mmol})$ and ethylene glycol $(10 \mathrm{mmol})$ were mixed with the STA-Ben $(50 \mathrm{mg})$. The mixture was exposed to microwave raditions. After irradiation of the mixture for a specified period, the contents were gradually cooled to room temperature. The completion of the reaction was checked by TLC. After confirming the completion of the reaction, the catalyst was recovered by filtration. The catalyst thus separated by filtration was washed $2-3$ times with absolute ethanol to remove organic matter. The residue obtained after evaporation of the solvent from the filtrate was purified using TLC/column chromatography with $\mathrm{CHCl}_{3}: \mathrm{MeOH}$ with increasing polarity. 


\section{Optimization of Reaction Conditions}

For the optimization of reaction conditions $10 \mathrm{mmol}$ of ethylene glycol and $10 \mathrm{mmol}$ of Benzaldehyde have been selected as reactants.

\section{Optimization of the Catalysts Amount}

Reactions have been performed using varying amount of different catalysts under uniform conditions (Table 1).

\section{Optimization of Time}

The reaction time has been optimized by performing reactions at regular intervals of time. After a certain time period there is not much increase in the yield. That time has been selected as optimum time (Table 2).

After optimization of time and amount of catalyst a number of acetal derivatives have been synthesized Table 3.

\section{Results and Discussion}

\subsection{Catalyst Characterization}

\section{X-Ray Diffraction}

The XRD pattern of Ben [33], Na-Ben and $\mathrm{H}^{+}$-Ben show a sharp peak at $2 \theta=5.93,6.83$ and 9.67 respectively corresponding to a d-value of $14.9 \AA, 12.9 \AA$ and 9.1 $\AA$. A decrease in the d-value of $2 \AA$ and $5.8 \AA$ is observed when interlayer cations $\left(\mathrm{Ca}^{2+}\right)$ are replaced by the

Table 1. Optimization of catalyst amount.

\begin{tabular}{|c|c|c|c|c|c|c|c|c|}
\hline \multirow{2}{*}{$\begin{array}{l}\text { S. } \\
\text { No. }\end{array}$} & \multirow{2}{*}{$\begin{array}{l}\text { catalyst } \\
(\mathrm{mg})\end{array}$} & \multirow{2}{*}{$\begin{array}{l}\text { Time, } \\
\text { Sec. }\end{array}$} & \multicolumn{6}{|c|}{$\begin{array}{l}\% \text { Yield of Benzaldehyde } \\
\text { acetal with various catalysts }\end{array}$} \\
\hline & & & Ben & Al-Ben & $\mathrm{H}^{+}$-Ben I & PAA-Ben & STA & STA-Ben \\
\hline 1 & 20 & 180 & 30 & 40 & 45 & 49 & 47 & 62 \\
\hline 2 & 30 & 180 & 36 & 47 & 52 & 57 & 55 & 72 \\
\hline 3 & 40 & 180 & 45 & 54 & 60 & 65 & 65 & 80 \\
\hline 4 & $\underline{50}$ & 180 & 50 & 60 & 65 & 70 & 68 & $\underline{88}$ \\
\hline 5 & 60 & 180 & 50 & 60 & 65 & 70 & 68 & 88 \\
\hline
\end{tabular}

Table 2. Optimization of time.

\begin{tabular}{ccc}
\hline S.No. & Time, Sec. & Yield, \% \\
\hline 01 & 90 & 66 \\
02 & 105 & 67 \\
03 & 120 & 70 \\
04 & 135 & 75 \\
05 & 150 & 80 \\
06 & 165 & 85 \\
07 & 180 & 88 \\
08 & 200 & 88 \\
\hline
\end{tabular}

Table 3. Products synthesized.

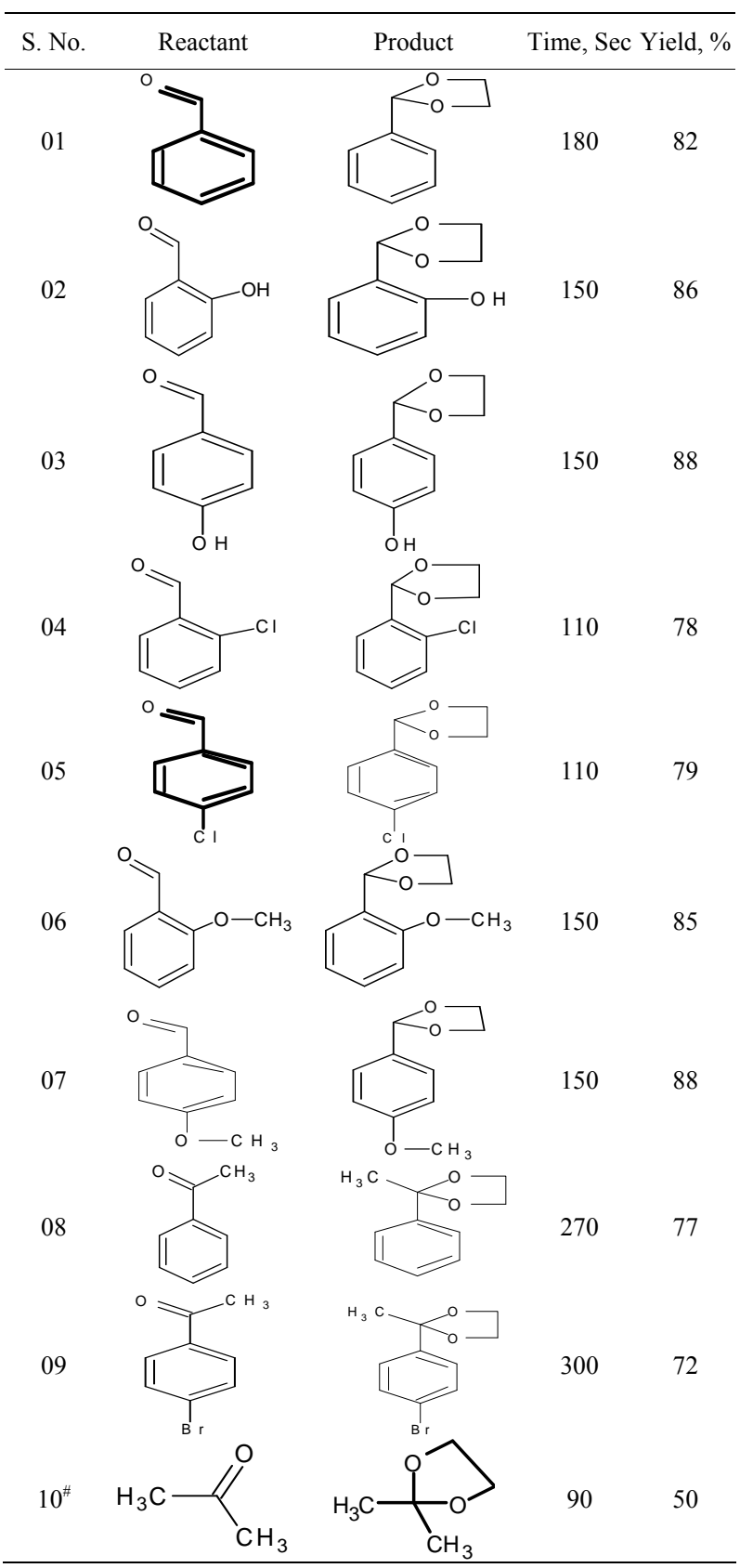

\#Reactant is highly volatile. Therefore, the yield is very low.

smaller ions, $\mathrm{Na}^{+}$and $\mathrm{H}^{+}$respectively. PAA-Ben, shows a further shift in the peak position, $2 \theta=5.30$ and a d-value of $16.6 \AA$ corresponding to an increase in the interlayer region by $7.5 \AA$ w.r.t $\mathrm{H}^{+}$-Ben confirms the intercalation of $\mathrm{Al}$ Keggin ion into the interlayer region of $\mathrm{H}^{+}$-Ben. The Al-Ben shows a peak at $2 \theta=5.20$ and a d-value of $16.9 \AA$ corresponding to an increase in the d-value of $4 \AA$ w.r.t Na-Ben thus confirming the intercalation of $\mathrm{Al}$ Keggin ion in the interlayer region of Na-Ben. STA-Ben, show a peak at $2 \theta=5.47$ corresponding to a d-value of 
16.1 $\AA$. This increase in the d-value $3.2 \AA$ w.r.t Na-Ben shows that STA is in the interlayer region of Na-Ben.

\section{Total Surface Area}

Total surface area studies have been performed by EGME method. Surface area values of Ben, Na-Ben, $\mathrm{H}^{+}-$ Ben, Al-Ben, PAA-Ben, STA-Ben are represented in the Table 4. Total surface area of Ben has been found to be $215 \mathrm{~m}^{2} / \mathrm{g}$. After conversion to Na-Ben total surface area has been found to be $121 \mathrm{~m}^{2} / \mathrm{g}$ which may be due to the decrease in d-spacing as indicated by XRD data. Total surface area of $\mathrm{H}^{+}$-Ben has been found to be $327 \mathrm{~m}^{2} / \mathrm{g}$. Although $\mathrm{Na}$ ions are replaced by smaller $\mathrm{H}^{+}$ions, but acid activation also causes the formation of small pores, consequently increasing the surface area $[34,35]$. Total surface area of Al-Ben has been found to be $295 \mathrm{~m}^{2} / \mathrm{g}$. Due to the intercalation of Al-Keggin ion the inner surface also becomes assessable. PAA-Ben has been found to have a total surface area of $350 \mathrm{~m}^{2} / \mathrm{g}$ which is again due to intercalation of Al-Keggin ion in $\mathrm{H}^{+}$-Ben. Total surface area of STA-Ben has been found to be $298 \mathrm{~m}^{2} / \mathrm{g}$ which again shows intercalation of STA.

\section{FT-IR}

Vibrational spectra of Ben, Na-Ben, $\mathrm{H}^{+}$-Ben, Al-Ben and PAA-Ben (Figures 1 and 2) indicate two strong absorption bands $\sim 3626 \mathrm{~cm}^{-1}$ and $\sim 3436 \mathrm{~cm}^{-1}$ corresponding to the stretching vibrations of the $\mathrm{O}-\mathrm{H}$ group originating from the surface adsorbed and interlayer water. The $\sim 1642 \mathrm{~cm}^{-1}$ band in these samples has been assigned to the H-O-H bending vibrations of water. The $\sim 1043$ $\mathrm{cm}^{-1}$ and $\sim 796 \mathrm{~cm}^{-1}$ bands are attributed to the stretching vibration of the Si-O bond. The $\sim 522 \mathrm{~cm}^{-1}$ and $\sim 466$ $\mathrm{cm}^{-1}$ bands have been assigned to the Si-O-Al and Si-OSi deformation vibrations respectively [31,32]. The STABen (Figure 3(b)) also shows the band in the similar region. The FT-IR spectra of STA (Figure 3(a)) shows an absorption band in the region of the $\sim 3141 \mathrm{~cm}^{-1}$ and have been assigned to the stretching vibrations originating from the $\mathrm{O}-\mathrm{H}$ groups present in the Keggin structure of STA. The absorption band at $\sim 1711 \mathrm{~cm}^{-1}$ has been assigned to the bending vibrations of the $\mathrm{O}-\mathrm{H}$ group. The

Table 4. Surface area of catalysts.

\begin{tabular}{cc}
\hline Catalysts & Total Surface Area, $\left(\mathrm{m}^{2} / \mathrm{g}\right)$ \\
\hline Ben & 215.0 \\
Na-Ben & 121.3 \\
Al-Ben & 295.2 \\
H$^{+}$-Ben & 327.2 \\
PAA-Ben & 350.1 \\
STA-Ben & 298.2 \\
\hline
\end{tabular}

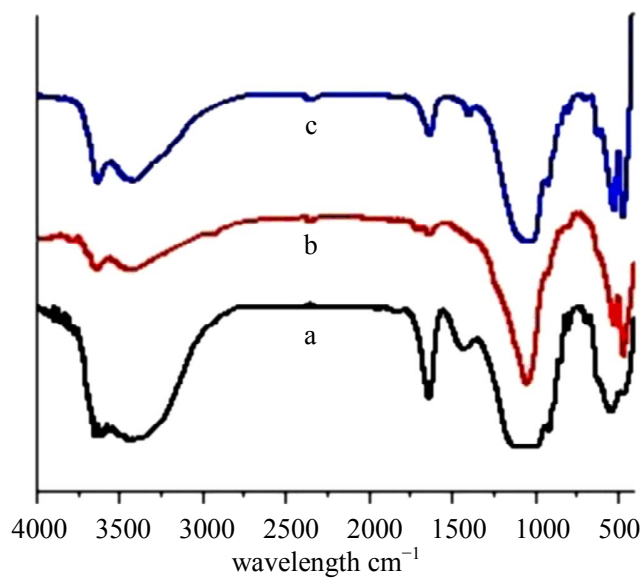

Figure 1. FTIR spectra of (a) Ben, (b) Na-Ben, (c) $\mathrm{H}^{+}$-Ben.

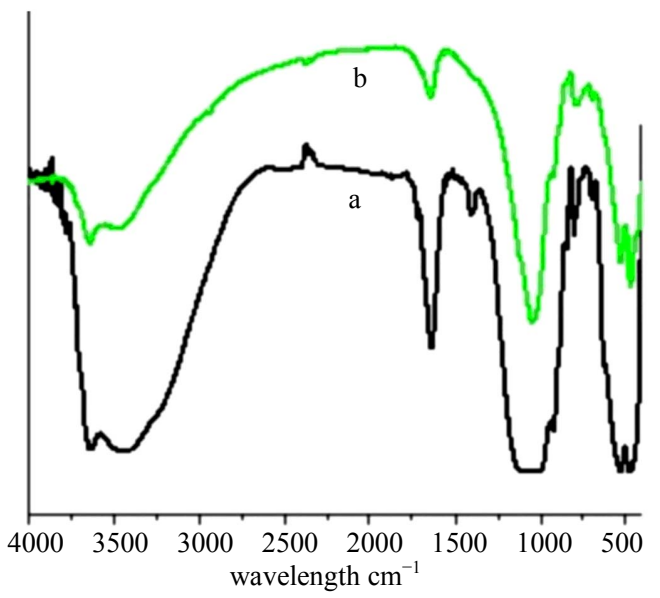

Figure 2. FTIR spectra of (a) Al-Ben, (b) PAA-Ben.

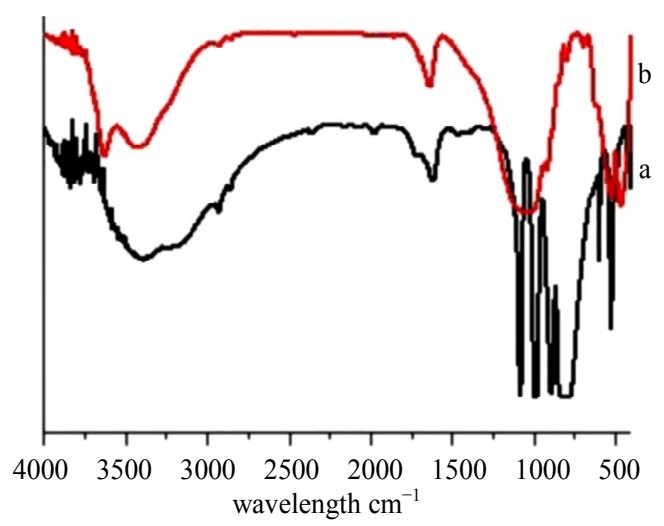

Figure 3. FTIR spectra of (a) STA, (b) STA-Ben.

fingerprint bands of the STA Keggin anion at 1081, 989, 890 and $793 \mathrm{~cm}^{-1}$, which could be assigned to the typical antisymmetrical stretching vibrations of $\mathrm{W}=\mathrm{O}, \mathrm{Si}-\mathrm{O}$, $\mathrm{W}-\mathrm{O}_{\mathrm{c}}-\mathrm{W}$ (Stretching Vibration involving corner sharing Oxygen atoms) and $\mathrm{W}-\mathrm{O}_{\mathrm{e}}-\mathrm{W}$ (Stretch Vib. involving edge sharing Oxygen atoms) respectively. 


\section{Thermal Method of Analysis}

The thermogram (TGA) of Ben, Na-Ben, $\mathrm{H}^{+}$-Ben (Figure 4) shows four step weight loss pattern. The first step, up to $180^{\circ} \mathrm{C}$, corresponds to dehydration of surface adsorbed water. The second step, $180^{\circ} \mathrm{C}$ to $550^{\circ} \mathrm{C}$, is attributed to dehydration of interlayer water. The third step $550^{\circ} \mathrm{C}$ to $675^{\circ} \mathrm{C}$, is attributed to the gradual dehydroxylation of clay layers. Beyond $675^{\circ} \mathrm{C}$ the clay loses its structure and practically shows no weight loss [31].

The thermogram (TGA) of PAA-Ben, Al-Ben (Figure 5) shows a similar four step weight loss pattern. The first step, up to $200^{\circ} \mathrm{C}$, corresponds to dehydration of surface adsorbed water. The second step, $200^{\circ} \mathrm{C}$ to $350^{\circ} \mathrm{C}$, is attributed to dehydration of interlayer water. The third step, $350^{\circ} \mathrm{C}$ to $600^{\circ} \mathrm{C}$, is attributed to the gradual dehydroxylation of clay layers. Beyond $600^{\circ} \mathrm{C}$ the clay loses its structure and practically shows no weight loss [31].

The TGA of pure STA (Figure 6(a)) shows two step

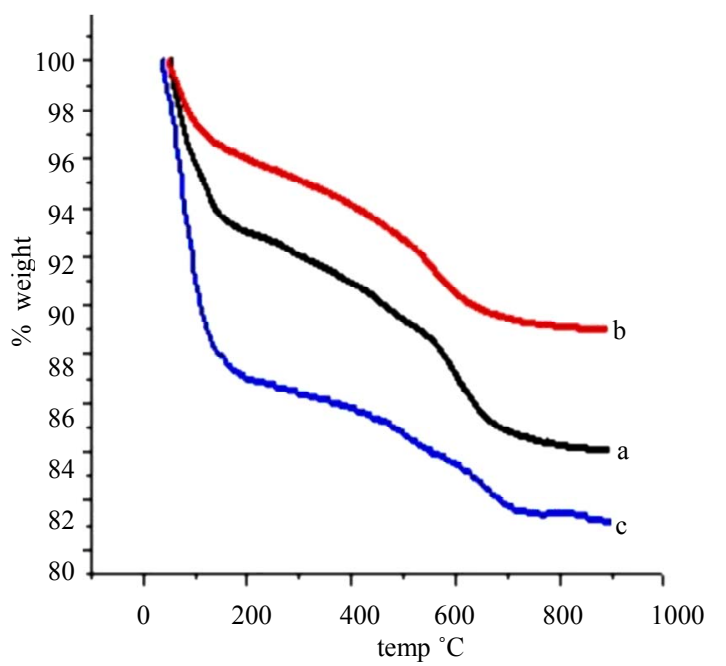

Figure 4. TGA studies of (a) Ben, (b) Na-Ben, (c) $\mathrm{H}^{+}$-Ben.

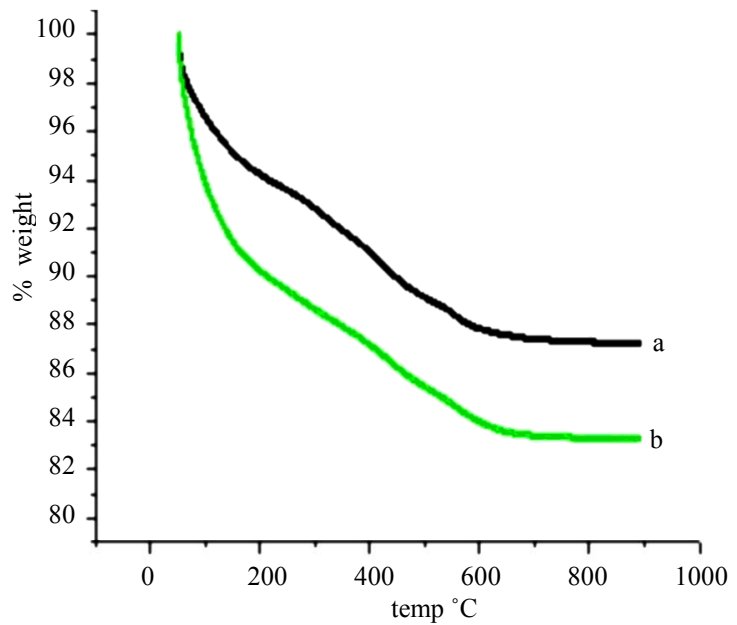

Figure 5. TGA studies of (a) Al-Ben, (b) PAA-Ben. weight losses. The first step, up to $300^{\circ} \mathrm{C}$, corresponds to the loss of water of crystallization. The second step, $300^{\circ} \mathrm{C}$ to $500^{\circ} \mathrm{C}$, shows weight loss corresponding to the decomposition of keggin unit of STA [33].

The TGA of STA-Ben (Figure 6(b)) shows four step weight loss patterns, the first step, up to $150^{\circ} \mathrm{C}$, corresponds to dehydration of surface water. The second step, $150^{\circ} \mathrm{C}$ to $350^{\circ} \mathrm{C}$, is attributed to dehydration of interlayer water. The third step, $350^{\circ} \mathrm{C}$ to $750^{\circ} \mathrm{C}$, is attributed to the dehydroxylation of clay layers and the loss of keggin ion structure The heteropoly acids are stable up to $500^{\circ} \mathrm{C}$ but after intercalation the catalyst becomes stable up to $750^{\circ} \mathrm{C}$.

\section{SEM with EDX Analysis}

The SEM-EDX pictures (magnification of 832X) of Ben and STA-Ben are represented in (Figures 7(a) and (b)). The SEM pictures of Ben and STA-Ben show no distinct change in the surface morphology and appear to have the layered structure. Therefore, it appears that the STA is not adsorbed on the surface of the clay but is in the layers of the clay. This fact is also supported by the XRD and IR studies. The SEM results are also supported by the EDX analysis. In both the cases surface composition consist of $\mathrm{Al}, \mathrm{Si}, \mathrm{O}, \mathrm{Mg}, \mathrm{Fe}, \mathrm{Ca} \& \mathrm{~K}$. No signal corresponding to $\mathrm{W}$ was supported by the EDX data which further shows that STA may be in the interlayers region.

\subsection{Characterization of Acetal Derivatives}

The acetal derivatives synthesized during the reaction has been characterized using FT-IR and NMR spectroscopy techniques.

1) Benzaldehyde acetal IR $\left(v\right.$ in $\left.\mathrm{cm}^{-1}\right) 3141$ (aromatic C-H), 1632, 1511, 1456 (aromatic ring), 1050 \& 1026 (C-O), 720 and 763 (mono. Subs.); ${ }^{1} \mathrm{H}$ NMR $\delta 7.9$ (d, 2H, $\mathrm{H}_{2,6 \text { Aromatic }}$ ), 7.6 ( $\mathrm{t}, 1 \mathrm{H}, \mathrm{H}_{4}$ Aromatic), $7.5-7.4$ ( $\mathrm{t}, 2 \mathrm{H}, \mathrm{H}_{3,5}$ Aromatic), $4.2\left(\mathrm{t}, 2 \mathrm{H}, \mathrm{CH}_{2}\right), 3.6\left(\mathrm{t}, 2 \mathrm{H}, \mathrm{CH}_{2}\right), 2.4(\mathrm{~s}, 1 \mathrm{H}$,

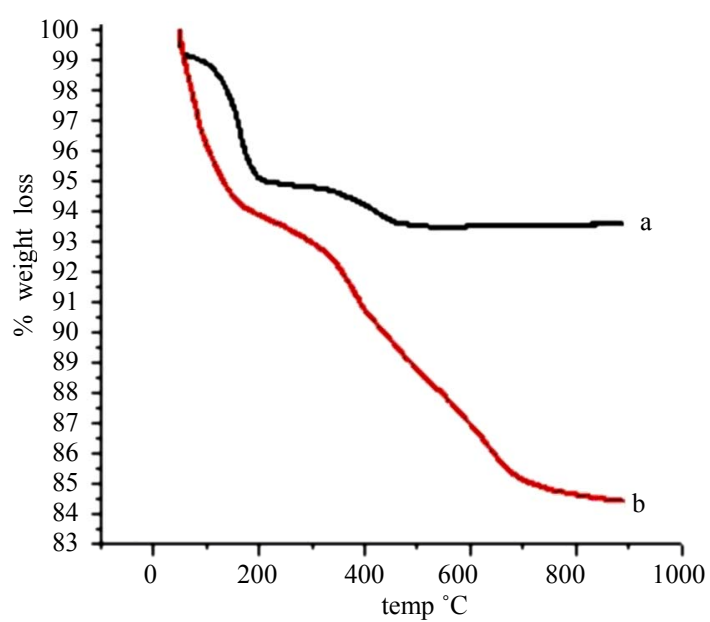

Figure 6. FTIR spectra of (a) STA, (b) STA-Ben. 


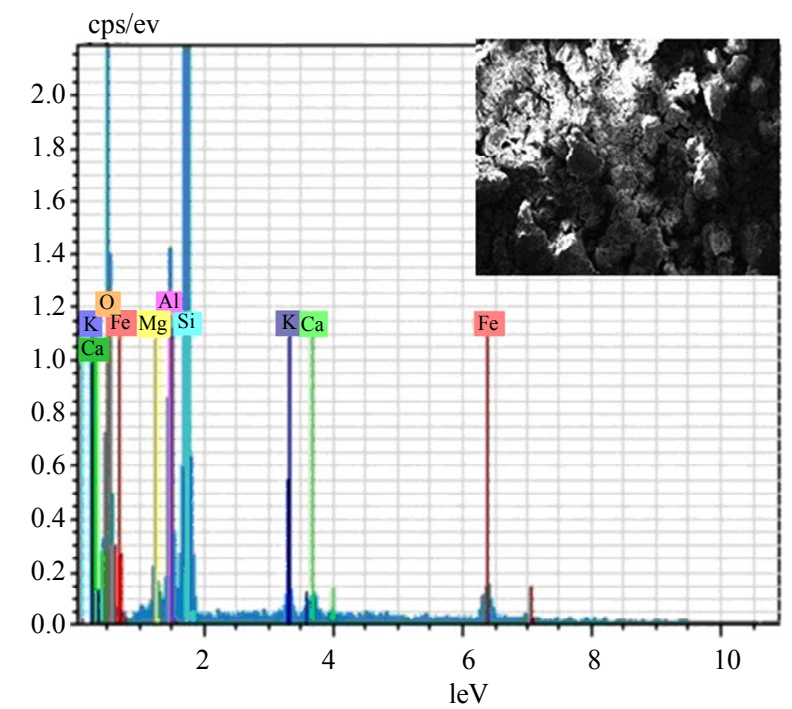

(a)

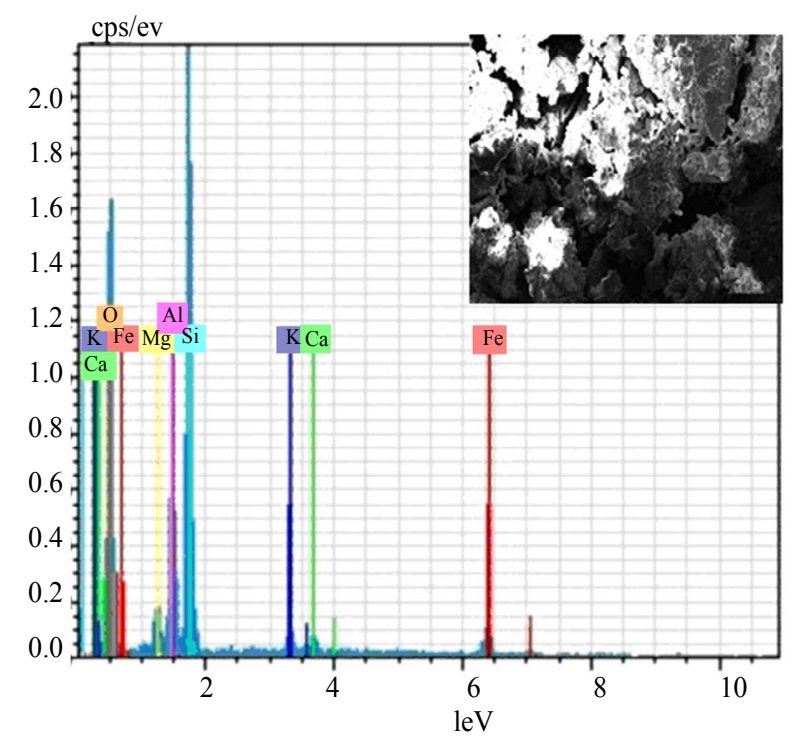

(b)

Figure 7. SEM-EDX of (a) Ben (b) STA-Ben.

$\mathrm{CH})$.

2) 2-hydroxy Benzaldehyde acetal IR $\left(v\right.$ in $\left.\mathrm{cm}^{-1}\right) 3411$ (O-H strech), 1551, 1456 (aromatic ring), $1003 \& 1026$ (C-O), 814 (p Subs.); ${ }^{1} \mathrm{H}$ NMR $\delta 10.1$ (s, 1H, OH), 7.6 (d, $1 \mathrm{H}, \mathrm{H}_{6}$ Aromatic $), 7.1\left(\mathrm{~d}, 1 \mathrm{H}, \mathrm{H}_{3}\right.$ Aromatic $), 6.6\left(\mathrm{~m}, 2 \mathrm{H}, \mathrm{H}_{4,5}\right.$ Aromatic), $3.6\left(\mathrm{t}, 2 \mathrm{H}, \mathrm{CH}_{2}\right), 3.5\left(\mathrm{t}, 2 \mathrm{H}, \mathrm{CH}_{2}\right), 3.4(\mathrm{~s}, 1 \mathrm{H}$, $\mathrm{CH})$.

3) 4-hydroxy Benzaldehyde acetal IR $\left(v\right.$ in $\left.\mathrm{cm}^{-1}\right) 3400$ (O-H strech), 1593,1464,1439 (aromatic ring), 1177, 1051 (C-O), 814 (p Subs.); ${ }^{1} \mathrm{H}$ NMR $\delta 10.3$ (s, $1 \mathrm{H}, \mathrm{OH}$ ), 7.4 (d, $1 \mathrm{H}, \mathrm{H}_{2,6}$ Aromatic), 6.8 - 6.9 (d, $2 \mathrm{H}, \mathrm{H}_{3,5}$ Aromatic), 3.8 (t, $\left.2 \mathrm{H}, \mathrm{CH}_{2}\right), 3.2\left(\mathrm{t}, 2 \mathrm{H}, \mathrm{CH}_{2}\right), 2.5(\mathrm{~s}, 1 \mathrm{H}, \mathrm{CH})$.

4) 2-chloro Benzaldehyde acetal IR $\left(v\right.$ in $\left.\mathrm{cm}^{-1}\right) 3179$ (aromatic C-H), 1589, 1491, 1463, 1400 (aromatic ring),
1273, 1093 (C-O), 750 (o-Subs.); ${ }^{1} \mathrm{H}$ NMR $\delta 7.8$ (d, 1H, $\left.\mathrm{H}_{6 \text { Aromatic }}\right), 7.4\left(\mathrm{~d}, 1 \mathrm{H}, \mathrm{H}_{3}\right.$ Aromatic $), 6.8-6.9\left(\mathrm{~m}, 2 \mathrm{H}, \mathrm{H}_{4,5}\right.$ Aromatic), $3.3\left(\mathrm{~m}, 4 \mathrm{H}, \mathrm{CH}_{2}\right), 2.6(\mathrm{~s}, 1 \mathrm{H}, \mathrm{CH})$.

5) 4-chloro Benzaldehyde acetal IR $\left(v\right.$ in $\left.\mathrm{cm}^{-1}\right) 3157$ (aromatic C-H), 1595, 1486, 1401 (aromatic ring), 1272, 1175 (C-O), 849 (p Subs.); ${ }^{1} \mathrm{H}$ NMR $\delta 7.7$ (d, 2H, $\mathrm{H}_{2,6}$ Aromatic), $7.4\left(\mathrm{~d}, 2 \mathrm{H}, \mathrm{H}_{3,5}\right.$ Aromatic $), 4.42\left(\mathrm{~m}, 4 \mathrm{H}, \mathrm{CH}_{2}\right), 4.44$ (s, 1H, CH).

6) 2-methoxy Benzaldehyde acetal IR $\left(v\right.$ in $\left.\mathrm{cm}^{-1}\right) 3100$ (aromatic $\mathrm{C}-\mathrm{H}$ ), 1606, 1511, 1459 (aromatic ring), 1258, 1169 (C-O), 770 (o-Subs.); ${ }^{1} \mathrm{H}$ NMR $\delta 7.8$ (d, $1 \mathrm{H}, \mathrm{H}_{6}$ Aromatic), $7.4\left(\mathrm{~d}, 1 \mathrm{H}, \mathrm{H}_{3}\right.$ Aromatic $), 6.8-6.9\left(\mathrm{~m}, 2 \mathrm{H}, \mathrm{H}_{4,5}\right.$ aromatic) $3.7\left(\mathrm{~m}, 4 \mathrm{H}, \mathrm{CH}_{2}\right), 3.6\left(\mathrm{~s}, 3 \mathrm{H}, \mathrm{OCH}_{3}\right), 2.6(\mathrm{~s}, 1 \mathrm{H}$, $\mathrm{CH})$.

7) 4-methoxy Benzaldehyde acetal IR $\left(v\right.$ in $\left.\mathrm{cm}^{-1}\right) 3041$ (aromatic C-H), 1511, 1457 (aromatic ring), 1276, 1259 (C-O), 848 (P-Subs.); ${ }^{1} \mathrm{H}$ NMR $\delta 7.9$ (d, 2H, $\mathrm{H}_{2,6}$ Aromatic), $6.9\left(\mathrm{~d}, 2 \mathrm{H}, \mathrm{H}_{3,5}\right.$ Aromatic $), 3.8\left(\mathrm{~m}, 4 \mathrm{H}, \mathrm{CH}_{2}\right), 3.8(\mathrm{~s}, 3 \mathrm{H}$, $\left.\mathrm{OCH}_{3}\right), 2.4(\mathrm{~s}, 1 \mathrm{H}, \mathrm{CH})$.

8) Acetophenone acetal IR ( $v$ in $\left.\mathrm{cm}^{-1}\right) 3127$ (aromatic C-H), 1568, 1464, 1473 (aromatic ring), 1026, 1006 (C-O), 692, 763 (monoSubs.); ${ }^{1} \mathrm{H}$ NMR $\delta 7.6$ (m, 3H,

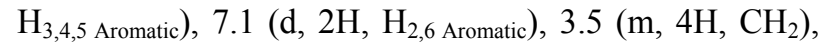
$2.5\left(\mathrm{~s}, 3 \mathrm{H}, \mathrm{CH}_{3}\right)$.

9) 4-bromo acetophenone acetal IR $\left(v\right.$ in $\left.\mathrm{cm}^{-1}\right) 3107$ (aromatic C-H), 1598, 1498 (aromatic ring), 1027 (C-O), 824 (p-Subs.), 628 (C-Br); ${ }^{1} \mathrm{H}$ NMR $\delta 7.5$ (d, 2H, $\mathrm{H}_{2,6}$ Aromatic), $7.1\left(\mathrm{~d}, 2 \mathrm{H}, \mathrm{H}_{3,5}\right.$ Aromatic), $4.3\left(\mathrm{t}, 2 \mathrm{H}, \mathrm{CH}_{2}\right), 4.2$ (t, $\left.2 \mathrm{H}, \mathrm{CH}_{2}\right), 2.3\left(\mathrm{~s}, 3 \mathrm{H}, \mathrm{CH}_{3}\right)$.

10) Acetone acetal IR $\left(v\right.$ in cm $\left.{ }^{-1}\right) 2923,2853(\mathrm{C}-\mathrm{H}$ strech), 1256, $1204(\mathrm{C}-\mathrm{O}) ;{ }^{1} \mathrm{H}$ NMR $\delta 3.6\left(\mathrm{~m}, 4 \mathrm{H}, \mathrm{CH}_{2}\right)$, $2.3\left(\mathrm{~s}, 6 \mathrm{H}, \mathrm{CH}_{3}\right)$.

\section{Reusability of STA-Ben}

The reusability of STA-Ben has been investigated up to six repeated cycles using synthesis of Acetal derivative of Benzaldehyde. The catalyst, STA-Ben, was washed with $\mathrm{MeOH}$ after every cycle and was characterized using FT-IR, TGA, DSC, XRD, SEM and EDX etc. techniques. No noticeable changes were observed even after six cycles, which not only indicates the stability of the catalyst, but also confirms that the catalyst can be reused. The product/s, after separation and isolation, was characterized and the yield in each case was calculated (Figure 8). The variation in the yield was found to be in the range of $82 \%$ to $62 \%$. The catalyst was characterized after the $6^{\text {th }}$ cycle of reaction and following observations were made.

The SEM picture (Figure 9) does not show any change in the surface morphology, the layered structure is maintained. The EDX data (Figure 9) indicates the same elemental composition as earlier, i.e. $\mathrm{Al}, \mathrm{Si}, \mathrm{O}, \mathrm{Mg}$, $\mathrm{Fe}, \mathrm{Ca}, \mathrm{K}$ and $\mathrm{Na}$. 
The thermal stability of the catalyst was found to be unaffected after reuse. (Figure 10). XRD and FTIR data (Figure 11) of STA-Ben has been found to have no significant change.

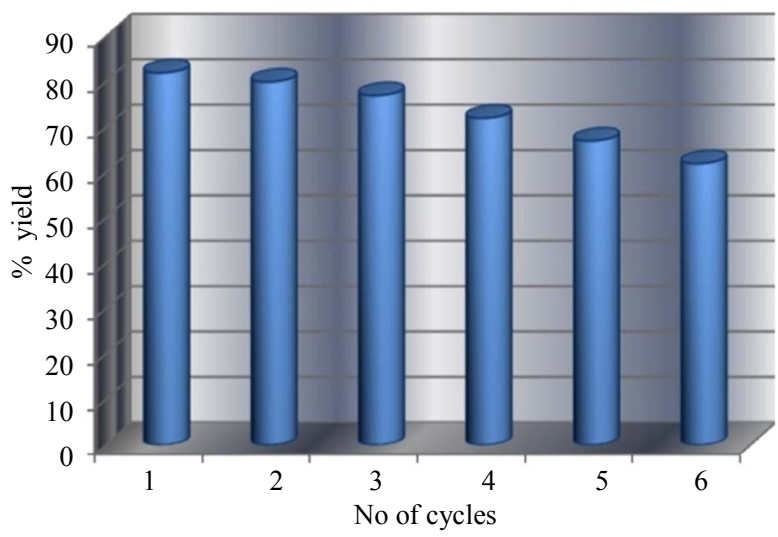

Figure 8. Reusability of STA-Ben up to 6 repeated cycles.

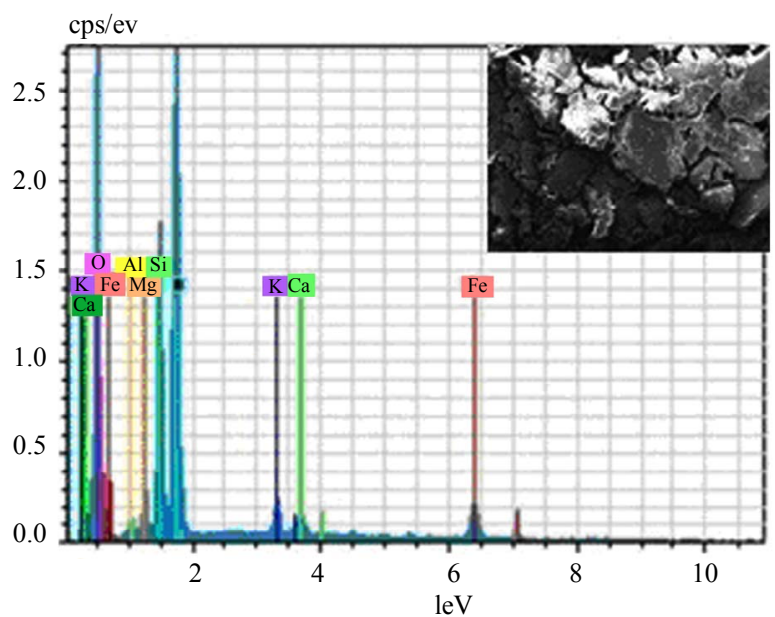

Figure 9. SEM-EDX of STA-Ben after $6^{\text {th }}$ cycle.

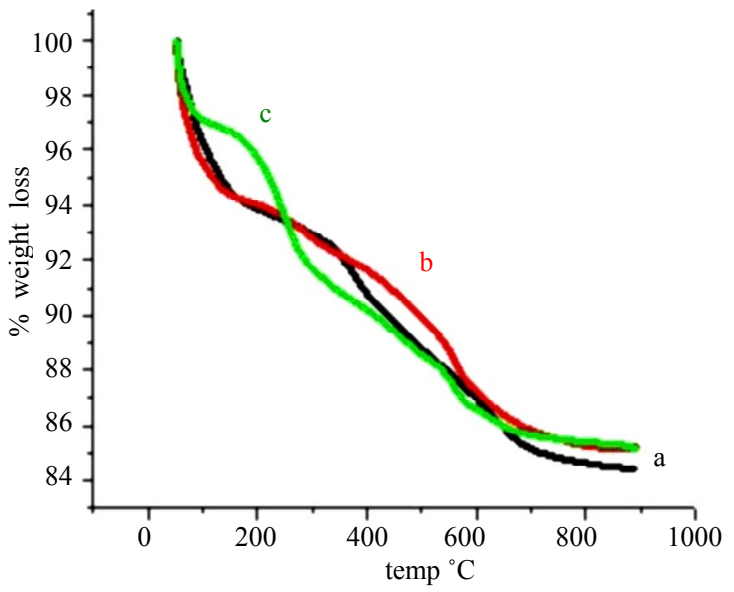

Figure 10. TGA studies of (a) STA-Ben, (b) STA-Ben after $1^{\text {st }}$ cycle, (c) STA-Ben after $6^{\text {th }}$ cycle.

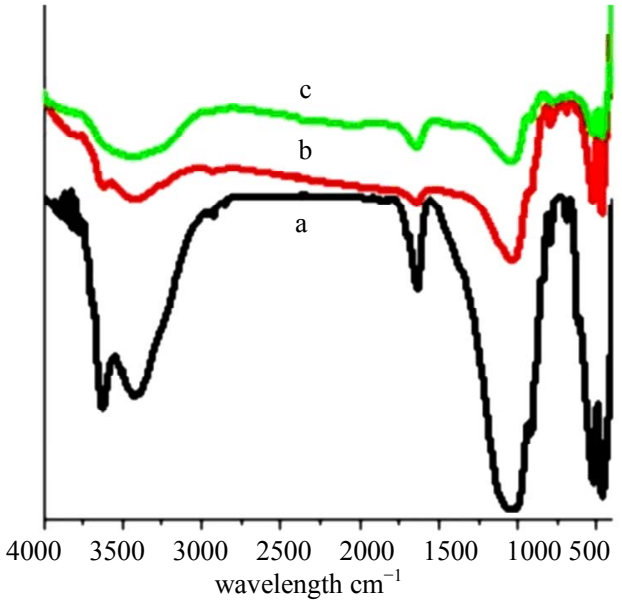

Figure 11. FTIR spectra of (a) STA-Ben, (b) STA-Ben after $1^{\text {st }}$ cycle, (c) STA-Ben after $6^{\text {th }}$ cycle.

\section{Conclusion}

We have synthesized STA intercalated Bentonite which proved to be a highly efficient, reusable and environmental benign catalyst for synthesis of acetal derivatives of aldehydes and ketones.

\section{REFERENCES}

[1] J. Cossy, H. Rakotoarisoa, P. Kahnand and J. R. Desmurs, "A One-Pot Synthesis Of Functionalized 2,2-Disubstituted 2H-1-Benzopyrans," Tetrahedron Letters, Vol. 39, No. 52, 1998, pp. 9671-9674. http://dx.doi.org/10.1016/S0040-4039(98)02266-7

[2] A. T. Khan, E. Mondal, P. R. Sahu and S. Islam, "Nickel(II) Chloride as an Efficient and Useful Catalyst for Chemoselective Thioacetalization of Aldehydes," Tetrahedron Letters, Vol. 44, No. 5, 2003, pp. 919-922. http://dx.doi.org/10.1016/S0040-4039(02)02771-5

[3] P. Datta, H. B. Borate, A. Sudalai, T. Ravlndranathan and V. H. Deshpande, "Natural Kaolinitic Clay: A Remarkable Reusable Solid Catalyst for the Selective Functional Protection of Aldehydes and Ketones," Tetrahedron Letters, Vol. 37, No. 26, 1996, pp. 4605-4608. http://dx.doi.org/10.1016/0040-4039(96)00888-X

[4] B. K. Banik, M. Chapa, J. Marquez and Magda Cardona, "A Remarkable Iodine-Catalyzed Protection of Carbonyl Compounds," Tetrahedron Letters, Vol. 46, No. 13, 2005, pp. 2341-2343. http://dx.doi.org/10.1016/j.tetlet.2005.01.176

[5] B. Perio, M. J. Dozias, P. Jacquault and J. Hamelin, "Solvent Free Protection of Carbonyl Group under Microwave Irradiation," Tetrahedron Letters, Vol. 38, No. 45, 1997, pp. 7867-7870. http://dx.doi.org/10.1016/S0040-4039(97)10149-6

[6] S. K. De, "Cobalt(II)Chloride Catalyzed Chemoselective Thioacetalization of Aldehydes," Tetrahedron Letters, Vol. 45, No. 5, 2004, pp. 1035-1036. 
http://dx.doi.org/10.1016/j.tetlet.2003.11.082

[7] J. W. Ralls, R. M. Dodson and B. Riegel, "Addition of Mercaptans to Unsaturated Steroid Ketones," Journal of the American Chemical Society, Vol. 71, No. 10, 1949, pp. 3320-3325. http://dx.doi.org/10.1021/ja01178a014

[8] E. Mondal, P. R. Sahu and A. T. Khan, "A Useful and Catalytic Method for Protection of Carbonyl Compounds into the Corresponding 1,3-Oxathiolanes and Deprotection to the Parent Carbonyl Compounds," Synlett, Vol. 3, No. 3, 2002, pp. 463-467. http://dx.doi.org/10.1055/s-2002-20466

[9] P. K. Mandal and S. C. Roy," Ceric Ammonium Nitrate as a Convenient Catalyst for Chemoselective Thioacetalisation," Tetrahedron, Vol. 51, No. 28, 1995, pp. 78237828. http://dx.doi.org/10.1016/0040-4020(95)00399-S

[10] S. Gogoi, J. C. Borah and N. C. Barua, "Montmorillonite K-10 Clay as an Efficient Solid Catalyst for Chemoselective Protection of Carbonyl Compounds as Oxathiolanes with 2-Mercaptoethanol," Synlett, Vol. 9, No. 9, 2004, pp. 1592-1594. http://dx.doi.org/10.1055/s-2004-829054

[11] J. S. Yadav, B. V. S. Reddy and G. Kondaji, "Eco-Friendly and Highly Chemoselective 1,3-Oxathio-and 1,3-Dithioacetalization of Aldehydes Using Ionic Liquids," Chemistry Letters, Vol. 32, No. 8, 2003, pp. 672-673. http://dx.doi.org/10.1246/cl.2003.672

[12] L. Jankovic and P. Komadel , "Metal Cation-Exchanged Montmorillonite Catalyzed Protection of Aromatic Aldehydes with Ac2O," Journal of Catalysis, Vol. 218, No. 1, 2003, pp. 227-233.

http://dx.doi.org/10.1016/S0021-9517(03)00138-6

[13] U. V. Desai, T. S. Thopate, D. M. Pore and P.P. Wadgaonkar, "An Efficient, Solvent-Free Method for the Chemoselective Synthesis of Acylals from Aldehydes and Their Deprotection Catalyzed by Silica Sulfuric Acid as a Reusable Solid Acid Catalyst," Catalysis Communications, Vol. 7, No. 7, 2006, pp. 508-511. http://dx.doi.org/10.1016/j.catcom.2005.12.028

[14] S. Chandrasekhar, M. Takhi, Y. R. Reddy, S. Mohapatra, C. R. Rao and K. V. Reddy, "Tacl5-Silicagel and Tacl5 as New Lewis Acid Systems for Selective Tetrahydropyranylation of Alcohols and Thioacetalisation, Trimerisation and Aldolisation of Aldehydes," Tetrahedron, Vol. 53, No. 44, 1997, pp. 14997-15004.

[15] M. khenkin, L. Weiner and R. Neumann, "Selective Ortho Hydroxylation Of Nitrobenzene with Molecular Oxygen Catalyzed by the H5pv2mo10o40 Polyoxometalate," Journal of the American Chemical Society, Vol. 127, No. 128, 2005, pp. 9988-9989.

http://dx.doi.org/10.1021/ja051286g

[16] A. M. Khenkin and R. Neumann, "Oxygen Transfer from Sulfoxides: Selective Oxidation of Alcohols Catalyzed by Polyoxomolybdates," The Journal of Organic Chemistry, Vol. 67, No. 20, 2002, pp. 7075-7079. http://dx.doi.org/10.1021/jo0255577

[17] T. Okuhara, N. Mizuno and M. Misono, "Catalytic Chemistry of Heteropoly Compounds," Advances in Catalysis, Vol. 41, 1996, pp. 113-252. http://dx.doi.org/10.1016/S0360-0564(08)60041-3
[18] I. V. Kozhevnikov, "Catalysis by Heteropoly Acids and Multicomponent Polyoxometalates in Liquid-Phase Reactions," Chemical Reviews, Vol. 98, No. 1, 1998, pp. 171-198. http://dx.doi.org/10.1021/cr960400y

[19] I. V. Kozhevnikov, "Fine Organic Synthesis with the Aid of Heteropolycompounds," Russian Chemical Reviews, Vol. 62, No. 5, 1993, p. 473. http://dx.doi.org/10.1070/RC1993v062n05ABEH000028

[20] I. V. Kozhevnikov, "Catalysts for Fine Chemicals, Catalysis by Polyoxometalates," Wiley, Chichester, 2002.

[21] M. N. Timofeeva, "Acid Catalysis by Heteropoly Acids," Applied Catalysis A: General, Vol. 256, No. 1-2, 2003, pp. 19-35. http://dx.doi.org/10.1016/S0926-860X(03)00386-7

[22] J. M. Adams, "Synthetic Organic Chemistry Using Pillared, Cation-Exchanged and Acid-Treated Montmorillonite Catalysts-A Review," Applied Clay Science, Vol. 2, No. 4, 1987, pp. 309-342. http://dx.doi.org/10.1016/0169-1317(87)90039-1

[23] G. Brain, A. Loupy and D. Villemin, "Microwave Activation of Reactions on Inorganic Solid Supports," In: K. Smith, Ed., Solids Supports and Catalysis in Organic Synthesis, Ellis Horwood, Chichester, 1992, pp. 100-122.

[24] L. Fowden, R. M. Barrer and P. B. Tinker, "Clay Minerals: Their Structure, Behaviour and Use," The Royal Society, London, 1984.

[25] E. González and A. Moronta, "The Dehydrogenation of Ethylbenzene to Styrene Catalyzed by a Natural and an Al-Pillared Clays Impregnated with Cobalt Compounds: A Comparative Study," Applied Catalysis A: General, Vol. 258, No. 1, 2004, pp. 99-105. http://dx.doi.org/10.1016/j.apcata.2003.08.004

[26] M. Kurian and S. Sugunan, "Characterisation of the Acid-Base Properties of Pillared Montmorillonites," Microporous and Mesoporous Materials, Vol. 83, No. 1-3, 2005, pp. 25-34.http://dx.doi.org/10.1016/j.micromeso.2005.03.001

[27] H. J. Chae, I.-S. Nam, S. W. Ham and S. B. Hong, "Physicochemical Characteristics of Pillared Interlayered Clays," Catalysis Today, Vol. 68, No. 1-3, 2001, pp. 3140. http://dx.doi.org/10.1016/S0920-5861(01)00320-0

[28] B. Tyagi, C. D. Chudasama and R. V. Jasra, "Characterization of Surface Acidity of an Acid Montmorillonite Activated with Hydrothermal, Ultrasonic and Microwave Techniques," Applied Clay Science, Vol. 31, No. 1-2, 2006, pp. 16-28. http://dx.doi.org/10.1016/j.clay.2005.07.001

[29] P. Salerno, M. B. Asenjo and S. Mendioroz, "Influence of Preparation Method on Thermal Stability and Acidity of Al-PILCs," Thermochimica Acta, Vol. 379, No. 1-2, 2001, pp. 101-109. http://dx.doi.org/10.1016/S0040-6031(01)00608-6

[30] W. O. Parker and I. Kiricsi Jr., "Aluminum Complexes in Partially Hydrolyzed Aqueous $\mathrm{A}_{1 C} 1_{3}$ Solutions Used to Prepare Pillared Clay Catalysts," Applied Catalysis A, Vol. 121, No. 1, 1995, pp. L7-L11. http://dx.doi.org/10.1016/0926-860X(95)85005-8

[31] E. M. Araujo, T. J. A. Melo, L. N. L. Santana, G. A. Ne- 
ves, H. C. Ferreira, H. L. Lira, L. H. Carvalho, M. M. Avila Jr., M. K. G. Ponte and I. S. Araujo, "The Influence of Organo-Bentonite Clay on The Processing and Mechanical Properties of Nylon 6 and Polystyrene Composites," Materials Science and Engineering: B, Vol. 112, No. 2-3, 2004, pp. 175-178.

http://dx.doi.org/10.1016/j.mseb.2004.05.027

[32] J. L. Valverde, P. Canizares, M. R. Sun Kou and C. B. Molina, "Enhanced Thermal Stability of Al-Pillared Smectites Modified with Ce and La," Clays and Clay Minerals, Vol. 48, No. 4, 2000, pp. 424-432. http://dx.doi.org/10.1346/CCMN.2000.0480402

[33] M. M. M. Abd El-Wahab and A. A. Said, "Phosphomolybdic Acid Supported on Silica Gel and Promoted with
Alkali Metal Ions as Catalysts for the Esterification of Acetic Acid By Ethanol," Journal of Molecular Catalysis A: Chemical, Vol. 240, No. 1-2, 2005, pp. 109-118. http://dx.doi.org/10.1016/j.molcata.2005.06.038

[34] N. Yildiz, Z. Aktas and A. Calimli, "Sulphuric Acid Activation of a Calcium Bentonite," Particulate Science and Technology, Vol. 22, No. 1, 2004, pp. 21-33. http://dx.doi.org/10.1080/02726350490422392

[35] J. Temuujin, Ts. Jadambaa, G. Burmaa, Sh. Erdenechimeg and J. Amarsanaa, "Characterisation of Acid Activated Montmorillonite Clay from Tuulant (Mongolia)," Ceramics International, Vol. 30, No. 2, 2004, pp. 251255. http://dx.doi.org/10.1016/S0272-8842(03)00096-8 